\title{
Azelnidipine protects myocardium in hyperglycemia-induced cardiac damage
}

\author{
Vasundhara Kain ${ }^{1 \dagger}$, Sandeep Kumar ${ }^{1 \dagger}$, Amrutesh S Puranik², Sandhya L Sitasawad ${ }^{1 *}$
}

\begin{abstract}
Background: Azelnidipine (AZL), a long-acting dihydropyridine-based calcium antagonist, has been recently approved and used for treating ischemic heart disease and cardiac remodeling after myocardial infarction, however, its effect on hyperglycemia-induced cardiac damage has not been studied.

Methods: This study examined the effect of AZL on circulating markers of cardiac damage, altered lipid and cytokines profile and markers of oxidative stress including homocysteine in diabetic rats.

Results: STZ induced diabetes caused a significant increase in blood glucose levels. It also resulted in an increase in the levels of homocysteine and cardiac damage markers, like Troponin-1, CK-MB, CK-NAC, uric acid, LDH and alkaline phosphatase. Moreover, there was an increase in the levels of proinflammatory cytokines like TNF- $\alpha$, IFN- $\gamma$, and TGF- $\beta$ and decrease in the levels of IL-4 and IL-10. Additionally, there was increase in the levels of cholesterol, triglycerides, $L D L, V L D L$ and a decrease in $\mathrm{HDL}$ in these animals. There was an altered antioxidant enzyme profile which resulted in a notable increase in the levels of oxidative stress markers like lipid peroxides, nitric oxide and carbonylated proteins. Compared with the untreated diabetic rats, $A Z L$ treatment significantly reduced the levels of troponin-1 ( $P<0.05)$, CK-MB $(P<0.05)$, CK-NAC $(P<0.05)$, uric acid $(P<0.05), \mathrm{LDH}(P<0.05)$ and alkaline phosphatase $(P<0.05)$. It also reduced the levels of the TNF- $\alpha(P<0.05)$, IFN- $\gamma(P<0.05)$, and TGF- $\beta(P<0.05)$ and increased the levels of $I L-4(P<0.05)$. A significant decrease in the serum cholesterol $(P<0.05)$, triglycerides $(P<0.05), L D L(P<0.05), V L D L(P<0.05)$ and a significant rise in levels of HDL $(P<0.05)$ was also observed. Treatment with AZL corrected the distorted antioxidant enzyme profile resulting in a significant decrease in the levels of lipid peroxides, nitric oxide and carbonylated proteins.

Conclusion: Our results indicate that AZL treatment can reduce the risk of hyperglycemia induced metabolic disorders and its role can be further extended to explore its therapeutic potential in diabetic patients with cardiac complications.
\end{abstract}

\section{Background}

Improper management of metabolic disturbances especially altered lipid and protein metabolism in diabetes results in grave cardiovascular complications which causes increasing diabetes-related mortalities [1]. Dyslipidemia, oxidative stress and inflammatory injury are important interrelated factors responsible for the development of cardiomyopathy as they are known to promote the progression of premature atherosclerosis, coronary insufficiency and myocardial infarction [2].

\footnotetext{
* Correspondence: ssitaswad@nccs.res.in

† Contributed equally

'National Centre for Cell Science, NCCS Complex, Pune University Campus,

Ganeshkhind Road, Pune-411007, Maharashtra, India

Full list of author information is available at the end of the article
}

Various studies have correlated that the circulating markers of myocardial damage, pro-inflammatory cytokines, calcium dysregulation, oxidative stress and atherogenic lipids are elevated in diabetic patients [3-10].

Metabolically, the diabetic heart is characterized by diminished glucose utilization and increased fatty acid oxidation resulting in lipid accumulation in the myocardium $[11,12]$. This myocardial lipotoxicity results in alterations in the inflammatory cytokines levels and evokes a cascade of disparaging changes that leads to cardiac damage. Recently, proinflammatory cytokines like TNF- $\alpha$ and IFN- $\gamma$ have been shown to alter the calcium regulation and directly or indirectly reduce the myocardial contractility [13-18]. Likewise, the proinflammatory and profibrotic cytokine, TGF- $\beta$ contributes to

\section{() Biomed Central}


the in vivo cardiac electrical remodeling by decreasing cardiac muscle L-type calcium current and charge movement $[19,20]$. These cytokine-induced cascades of events mechanistically contribute to cardiomyocyte apoptosis possibly due to disturbance of calcium homeostasis via redox regulatory mechanisms leading to extensive myocyte cell death.

There is an alteration in the antioxidant enzyme levels which leads to oxidative stress as the production of reactive oxygen species (ROS) exceeds its scavenging. Oxidative stress directly leads to lipid peroxidation, protein carbonylation and cardiac fibrosis significantly contributing to pathophysiology of cardiac complications of diabetes [21-25]. It has been shown that increased calcium flux further aggravates oxidative stress and vice versa [26-29]. Thus the role of calcium channel blockers (CCBs) becomes extremely important for correcting this underlying phenomenon.

CCBs initially used to treat hypertension found additional beneficial implications in various conditions, such as angina pectoris, hypertrophic cardiomyopathy, pulmonary hypertension and diabetic cardiomyopathy [30]. There are 3 main classes-phenylalkylamines, benzothiazepines, and dihydropyridines (DHP) because of difference in their molecular structure, sites and modes of action, and effects on various other cardiovascular functions [31]. Primarily, the CCBs lower blood pressure through vasodilation and reduction of peripheral resistance and usually do not impair glucose metabolism or lipid profile and may even attenuate the development of arteriosclerotic lesions [30]. Inferring from these studies, it seems that calcium antagonists are also safe and effective as first-line or add-on therapy in diabetic hypertensive patients [32]. Thus, CCBs with lipid-lowering, antioxidative and/or anti-inflammatory activities may potentially prevent or delay the occurrence of diabetic cardiomyopathy.

AZL, a newly developed and commercially used novel long-acting DHP-based calcium antagonist has been reported to be effective in treating ischemic heart disease and cardiac remodeling after myocardial infarction (MI) [3] and reduce blood pressure without increasing the heart rate in patients with hypertension [33,34]. In the experimental animals, AZL revealed anti-atherosclerotic effects independent of its blood pressure-lowering actions [35]. In another study, AZL prevented the TNF-induced endothelial cell activation via its antioxidative properties [36]. AZL also inhibited $\mathrm{H}_{2} \mathrm{O}_{2}$-induced cell death in neonatal rat cardiomyocytes [37]. However, the effects of AZL on diabetes induced cardiac damage have not been studied.

In the light of the above findings, we chose to investigate the possible effect of AZL on the circulating markers of cardiac damage (troponin 1, CK-MB, CK-NAC, LDH, uric acid), oxidative stress (lipid peroxides, nitric oxide, carbonyl content), antioxidant enzyme (superoxide dismutase, catalase and reduced glutathione), serum hcy, proinflammatory and anti-inflammatory cytokines (TNF- $\alpha$, IFN- $\gamma$, TGF- $\beta$, IL- 4 and IL10) and atherogenic lipid profile in STZ induced diabetic rats.

\section{Methods}

Six to eight-week-old male Wistar rats (NCCS, Pune, India) weighing 300 to $330 \mathrm{~g}$ were made diabetic by a single intraperitoneal injection of streptozotocin (STZ) (55 mg/kg, Sigma, St. Louis, MO) as described previously [23]. Control animals were treated with vehicle ( $0.1 \mathrm{~mol} / \mathrm{L}$ sodium citrate buffer, $\mathrm{pH} 4.5)$. Hyperglycemia (blood glucose $>200 \mathrm{mg} / \mathrm{dL}$ ) was confirmed 3 days post STZ injection using a glucometer (AccuCheck; Roche, Germany). Diabetic animals were treated with AZL suspended in 1\% carboxy methyl cellulose at a single daily dose of $5 \mathrm{mg} / \mathrm{kg}$, administered orally by gavage on the $4^{\text {th }}$ day of STZ treatment $(n=12)$ for 12 weeks. At the end of the study duration, rats were fasted overnight, anesthetized using $500 \mathrm{mg} / \mathrm{kg}$ dose of urethane and the blood was collected via heart puncture with a $19 \frac{1}{2}$ gauge needle. The animals were then euthanized by cervical dislocation. Urethane was selected in the present study as an anesthetic agent as a single dose induces long term anesthesia with minimal cardiovascular and respiratory system depression. It is a convenient one shot method for non-recovery studies and produces a level of surgical anesthesia and analgesia characterized by preservation of a number of cardiovascular reflexes [38]. All procedures were approved by Institutional Animal Care and Use Committee and complied with standards for the care and use of animal subjects, as stated in the Guide for the Care and Use of Laboratory Animals (Institute of Laboratory Resources, National Academy of Sciences, Bethesda, MD).

Heart was excised and the heart weight (HW) and left ventricular mass (LVM) was noted.

For the isolation of plasma, the blood was collected in EDTA-coated Vacutainer (BD Vacutainer ${ }^{\bullet}$, USA) was isolated after centrifuging blood in a pre-cooled centrifuge at $1500 \mathrm{rpm}$ for $10 \mathrm{~min}$ at $1500 \times \mathrm{g}$. For isolation of serum, the blood was allowed to clot at room temperature for 15 to 20 minutes then centrifuged for 10 minutes at $1000 \times \mathrm{g}$.

\section{Serum Insulin}

Serum insulin levels were measured by the High-range Rat Insulin ELISA kit from Mercodia AB, (Sweden) as per manufacturer's instructions [39]. 


\section{Quantification of hcy levels in the serum by High Performance Liquid Chromatography (HPLC)}

Serum hcy was analyzed by HPLC as described previously [40]. The HPLC system (Dionex, Germany) consisted of P-680 quaternary gradient pump, an ASI 100 autosampler, a universal chromatographic interface UCI-50 and fluorescence detector RF-2000 integrated by Chromeleon Software 6.70 coupled to $\mathrm{pH}$ stable reverse phase C18 column $(4.6 \times 250 \mathrm{~mm}$, Varian, Varian Inc). Thiol-specific fluorogenic reagent 4-(aminosulfonyl)-7fluoro-2,1,3-benzoxadiazole (ABD-F) was used as flurochrome. Mobile phase used was ammonium phosphate buffer $(0.01 \mathrm{M})$ and acetonitrile (80:20) with flow rate as $0.5 \mathrm{~mL}$ per min. The limit of detection of hcy (Sigma Inc, USA) was $500 \mathrm{nmol} \mathrm{L}^{-1}$.

\section{Cytokines assay}

TNF- $\alpha$, IFN- $\gamma$, TGF- $\beta$, IL- 4 and IL-10 in the plasma were determined by the sandwich ELISA method using a commercially available kit from BD OptEIA ELISA Set (BD Biosciences, USA) as per manufacturer's instructions. The data are expressed as picogram per milliliter. For each assay the cytokine standards were used each time to check the variation from plate to plate on different days of analyses.

\section{Biochemical Markers of Myocardial Injury in serum}

Estimation of total cholesterol, low density lipoprotein, high density lipoproteins, very low density lipoproteins, creatine kinase (CK-MB and CK-NAC), lactate dehydrogenase (LDH), uric acid and troponin I in the serum was done using appropriate kits on RA-50 semi auto analyzer by well standardized methods.

\section{Liver function tests}

Quantitative estimation of Alanine aminotranferease (ALT), aspartate aminotransferase (AST) and alkaline phosphatase was done using specific kit [Erba Diagnostics Mannheim GmBH, Germany] using RA -50 semi auto analyzer by well standardized methods [41].

\section{Mesurement of lipid peroxidation}

Determination of lipid peroxidation (nmole malondialdehyde/mg protein) was done spectrophotometrically using the thiobarbituric acid-reactive substance (TBARS) by the method of Uchiyama and Mihara [42] using 1,1,3,3-tetramethoxypropane as a standard.

\section{Estimation of antioxidant enzyme levels}

The level of SOD and catalase enzyme activities was measured using the SOD Assay Kit-WST and Catalase Assay kit (Sigma, St. Louis, MO) according to the manufacturer's instructions. The concentration of reduced glutathione (GSH) was determined according to Ellman [43]. All assays were performed in triplicate and on the same day to reduce inter-assay variation. Activities were normalized to protein in the sample using previously described spectrophotometric dye binding methods [44].

\section{Estimation of Nitrite oxide}

Nitric oxide was quantitated by using Griess Reagent Kit for Nitrite Determination (Molecular Probes, USA) as per manufacturer's instructions.

\section{Protein carbonyl assay}

The level of protein carbonyl groups was estimated according to the method of Levine et al. [45] with slight modifications. Briefly, the samples were incubated with 2,4-dinitrophenylhydrazine (DNPH) for $1 \mathrm{~h}$ followed by precipitation with trichloroacetic acid. After centrifugation, the pellets were washed with an ethanol-ethyl acetate mixture to remove the excess $\mathrm{DNPH}$, dissolved in guanidine hydrochloride solution $(6 \mathrm{~mol} / \mathrm{L})$ and the absorbance was measured at $370 \mathrm{~nm}$. The content of carbonyl groups was calculated using the molar extinction coefficient of 22,000 $(1 / \mathrm{cm} \mathrm{mol})$. The content of protein was assayed by the method of Lowry et al [46], using bovine serum albumin as standard.

\section{Statistical analysis}

Data are expressed as means \pm standard error (SE) and were analyzed using one-way analysis of variance and secondary analysis for significance with Tukey-Kramer post tests using Prism 4.0 GraphPad software (GraphPad, San Diego, CA, USA). A $p$ value less than 0.05 was considered statistically significant.

\section{Results}

\section{Characterization of animal groups}

Animals in the untreated STZ diabetic group displayed severe hyperglycemia, significant decrease in the levels of insulin and an increase in the LVM/BW ratio (as an index of ventricular hypertrophy). AZL treatment reduced the glucose levels although the levels remained elevated than the controls. AZL treatment also improved the levels of serum insulin. AZL treatment resulted in a significant decrease in the $\mathrm{LVM} / \mathrm{BW}$ ratio indicating that AZL treatment prevents left ventricular hypertrophy. The data for blood glucose, serum insulin, and $\mathrm{LVM} / \mathrm{BW}$ ratio has been tabulated in Table 1 . There was also a notable increase in the levels of total serum cholesterol, triglycerides, LDLs and VLDL. Levels of HDL decreased in the STZ-diabetic rats there by significantly increasing the total cholesterol to HDL ratio and HDL to LDL ratio. 
Table 1 Effect of AZL treatment on blood glucose, insulin, homocysteine and LVW/BW ratio in STZ-treated diabetic rats

\begin{tabular}{llll}
\hline Parameters & Control $(\mathbf{n}=\mathbf{1 0})$ & STZ $^{*}(\mathbf{n}=\mathbf{1 0})$ & AZL $(\mathbf{5} \mathbf{~ m g} / \mathbf{k g} / \mathbf{d a y}){ }^{* *}(\mathbf{n}=\mathbf{1 0})$ \\
\hline Blood Glucose $(\mathrm{mg} / \mathrm{dL})$ & $167.5 \pm 25.5$ & $517.5 \pm 45.5$ & $256.2 \pm 12.4$ \\
Serum Insulin $(\mathrm{ng} / \mathrm{mL})$ & $3.3 \pm 0.4$ & $0.42 \pm 0.3$ & $1.40 \pm 0.4$ \\
Homocysteine $(\mu \mathrm{M} / \mathrm{L})$ & $2.9 \pm 0.7$ & $26.5 \pm 4.4$ & $13.8 \pm 3.9$ \\
LWW/BW ratio $(\mathrm{mg} / \mathrm{g})$ & $3.5 \pm 0.12$ & $4.9 \pm 0.02$ & $3.4 \pm 0.43$ \\
\hline
\end{tabular}

Values are mean \pm SE. * means $p<0.05$ compared to control group, ${ }^{* *}$ means $p<0.05$ compared to STZ diabetic group.

\section{AZL treatment decreases the levels of Hcy}

Hcy concentration in blood has been predicted as a powerful prognostic marker of cardiac complications of diabetes [47]. STZ diabetic rat showed a significant increase in the levels of hcy which were significantly reduced after AZL treatment (Table 1).

\section{AZL treatment reduces the markers of cardiac damage}

Compared to the controls, the circulating markers of cardiac damage in STZ diabetic rat, showed a significant increase in the levels of serum troponin I (1.21 \pm 0.13 $\mathrm{ng} / \mathrm{mL}$ vs. $0.72 \pm 0.15 \mathrm{ng} / \mathrm{mL}), \mathrm{CK}-\mathrm{MB}(135.0 \pm 29.5$ IU/L vs. $37.50 \pm 9.9 \mathrm{IU} / \mathrm{L})$ and CK-NAC (1013.0 \pm 96.3 $\mathrm{IU} / \mathrm{L}$ vs. $81.21 \pm 32.43 \mathrm{IU} / \mathrm{L}), \mathrm{LDH}(407.0 \pm 64.72 \mathrm{IU} / \mathrm{L}$ vs. $95.0 \pm 10.99 \mathrm{IU} / \mathrm{L})$ and uric acid $(8.53 \pm 1.54 \mathrm{mg} / \mathrm{dL}$ vs. $3.93 \pm 0.5 \mathrm{mg} / \mathrm{dL})$. This notable increase was significantly reduced by AZL treatment. The levels of troponin I $(0.66 \pm 0.08 \mathrm{ng} / \mathrm{mL}), \mathrm{CK}-\mathrm{MB}(38.8 \pm 4.0 \mathrm{IU} / \mathrm{L})$, and CK-NAC (150.32 $\pm 61.2 \mathrm{IU} / \mathrm{L}), \mathrm{LDH}(61.50 \pm 21.0 \mathrm{IU} /$ $\mathrm{L})$, Uric acid $(2.1 \pm 0.93 \mathrm{mg} / \mathrm{dl})$ and alkaline phosphatase $(149.6 \pm 8.43 \mathrm{IU} / \mathrm{L})$ were significantly lower when compared with the STZ diabetic group (Figure 1).

\section{Improvement of proinflammatory cytokines after AZL treatment}

Compared to the controls, STZ diabetic rat demonstrated significantly increased levels of the pro-inflammatory cytokines TNF- $\alpha(389.1 \pm 46.2 \mathrm{pg} / \mathrm{mL}$ vs. $81.6 \pm 28.3 \mathrm{pg} / \mathrm{mL})$, IFN- $\gamma(299.3 \pm 42.9 \mathrm{pg} / \mathrm{mL}$ vs. $149.6 \pm 17.6 \mathrm{pg} / \mathrm{mL})$, TGF$\beta(2875.3 \pm 349.08 \mathrm{pg} / \mathrm{mL}$ vs. $1913.3 \pm 362.1 \mathrm{pg} / \mathrm{mL})$. There was a notable decrease in levels of IL-4 (63.8 \pm 11.1 $\mathrm{pg} / \mathrm{mL}$ vs. $105.9 \pm 24.2 \mathrm{pg} / \mathrm{mL})$ and IL-10 (462.4 \pm 31.2 pg/mL vs. $979.5 \pm 150.3 \mathrm{pg} / \mathrm{mL})$. AZL treatment prevented the increase in the levels of TNF- $\alpha(90.0 \pm 14.8 \mathrm{pg} / \mathrm{mL})$, IFN- $\gamma(200.2 \pm 38.1 \mathrm{pg} / \mathrm{mL})$, and TGF- $\beta(1892.4 \pm 321.0$ $\mathrm{pg} / \mathrm{mL})$. It also resulted in an increase in the levels of IL-4 $(132.1 \pm 22.9 \mathrm{pg} / \mathrm{mL})$, which was even higher than the controls (Figure 2). However, levels of IL-10 remained unchanged $(499.2 \pm 110.5 \mathrm{pg} / \mathrm{mL})$ in AZL treatment group when compared to STZ diabetic group.

Normalization of altered lipid profile after AZL treatment AZL had a significant effect on lowering triglyceride, cholesterol, LDL and VLDL levels and increasing HDL levels in diabetic rats (Table 2A). Diabetic rats treated with AZL also showed significant decreases in total cholesterol and total cholesterol/HDL ratio, as well as elevated levels of HDL cholesterol (Table 2B). All these levels were completely normalized after AZL treatment which suggests that AZL is far more effective in maintaining the lipid profile near to that of control in this animal model of diabetes.

\section{Effect of AZL on the markers of liver function}

Diabetes was found to increase the levels of the liver marker enzymes ALT $(60.7 \pm 8.8)$, AST $(86.7 \pm 10.5)$ and alkaline phosphatase $(330.0 \pm 12.51 \mathrm{IU} / \mathrm{L})$ compared with those of the controls viz. $37.5 \pm 11.5,27.7 \pm 2.5$ and $181.7 \pm 32.9 \mathrm{IU} / \mathrm{L}$, respectively. After treatment with AZL, the levels of ALT, AST and alkaline phosphatase were observed to be normalized at $27.5 \pm 5.2$ for ALT, $32.0 \pm 4.0$ for AST and $149.6 \pm 8.4$ IU/L for alkaline phosphatase, indicating that AZL treatment does not metabolically induce xenobiotic hepatotoxicity (Figure 3).

\section{Effect of AZL treatment on diabetes-Induced Oxidative Stress}

Lipid peroxides formation (nmol MDA/mg protein) which is a direct marker for oxidative stress increased significantly in the cardiac tissue of STZ group compared with the control (STZ $14.5 \pm 2.5$ vs. control $2.1 \pm$ $0.5, P<0.05)$. AZL treatment significantly reduced the levels of lipid peroxidation $(3.2 \pm 1.1, P<0.05)$ which was very close to the control group (Figure $4 \mathrm{~A})$. With respect to the control group the levels of carbonyl content (nmol/mg protein), another indicator of oxidative stress, were also increased in diabetic rat (STZ $44.2 \pm$ 4.5 vs. control $7.7 \pm 1.9, P<0.05)$ and AZL treatment significantly prevented this increase $(10.2 \pm 4.9, P<$ 0.05 ) (Figure $4 \mathrm{~B}$ ). Levels of nitric oxide, which is indicative of nitrosative stress $(\mu \mathrm{mol} / \mathrm{L})$, increased significantly in diabetic rat heart when compared to control (STZ $259.3 \pm 29.3$ vs. control $21.3 \pm 4.4, P<0.05)$. This nitric oxide level after AZL treatment were reduced $(29.55 \pm 11.3, P<0.05)$ and were close to control group (Figure 4C). 
A

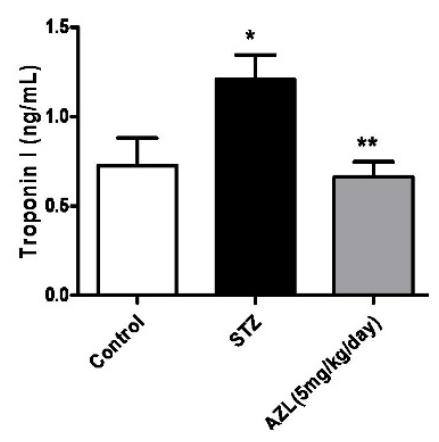

B

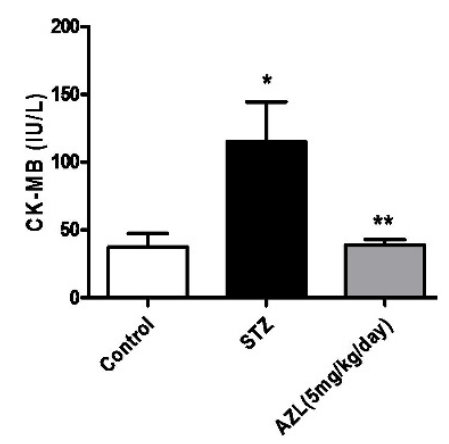

C

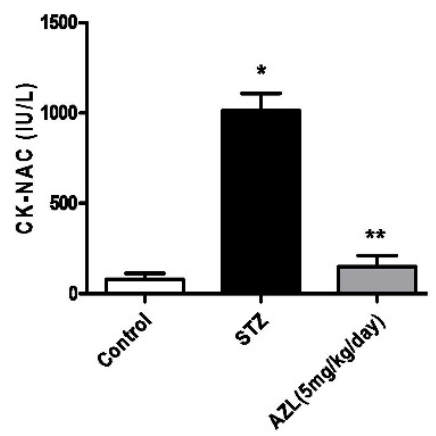

D

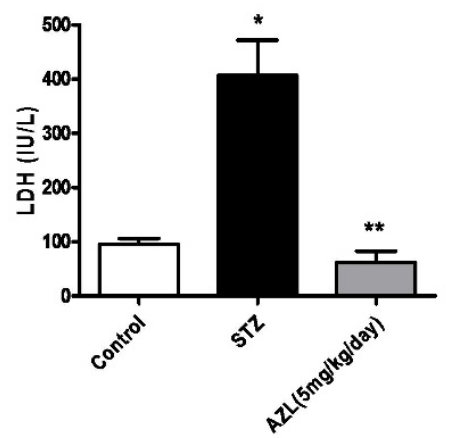

E

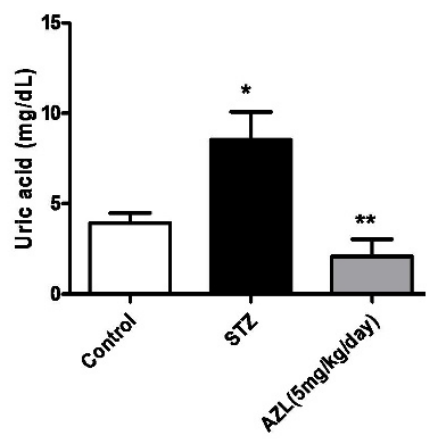

Figure 1 Effect of AZL treatment on serum cardiac markers in STZ-treated diabetic rats (A) Troponin I (B) CK-MB (C) CK-NAC (D) LDH (E) Uric acid levels. Values depict means \pm SE for at least $n=8$ animals in each group. ${ }^{*}$ means $p<0.01$ compared to control group and ${ }^{* *}$ means $p<0.01$ compared to STZ diabetic group

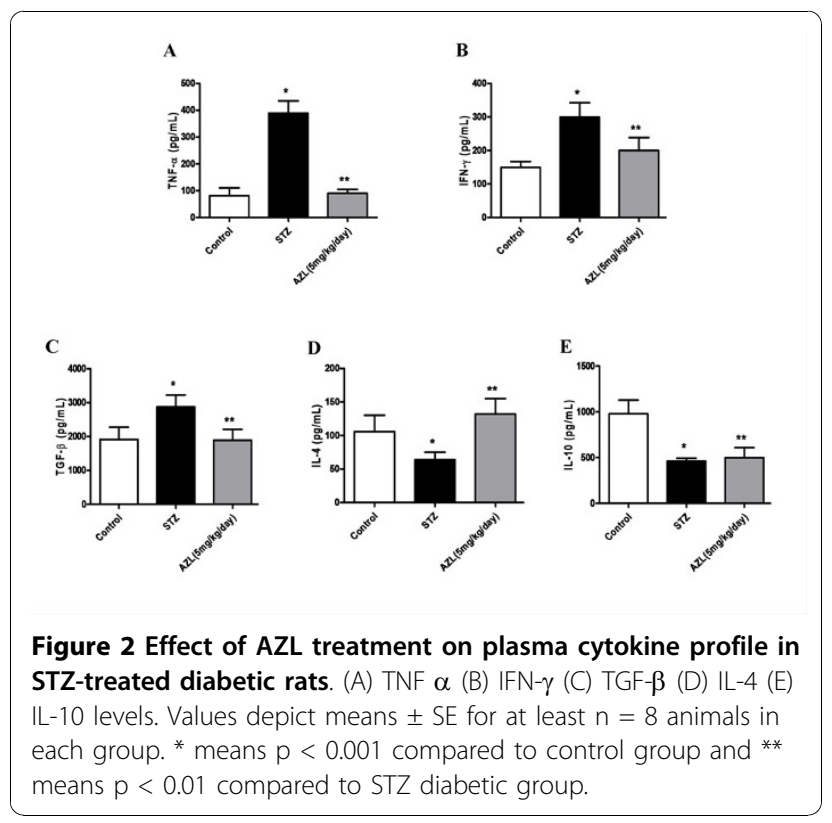

Table 2 (A) Effect of AZL treatment on serum lipid profile. B) Atherogenic risk marker and cardiovascular risk indicator

\begin{tabular}{llll}
\hline & CTRL & STZ & AZL(5 mg/kg/day) \\
\hline $\begin{array}{l}\text { SERUM CHOLESTEROL } \\
\text { (mg/dL) }\end{array}$ & $70.3 \pm 6.4$ & $165 \pm 9.6^{*}$ & $71 \pm 5.9^{\#}$ \\
$\begin{array}{l}\text { SERUM } \\
\text { TRIGLYCERIDES } \\
\text { (mg/dL) }\end{array}$ & $68 \pm 7.4$ & $146 \pm 12.5^{*}$ & $74 \pm 11.3^{\#}$ \\
HDL (mg/dL) & $46 \pm 3.5$ & $29 \pm 7.1^{*}$ & $48 \pm 5.2^{\#}$ \\
LDL (mg/dL) & $34 \pm 3.9$ & $66 \pm 7.9^{*}$ & $41 \pm 5.0^{\#}$ \\
VLDL (mg/dL) & $13.6 \pm 3$ & $29.2 \pm 5.5^{*}$ & $14.8 \pm 5.1^{\#}$ \\
Total Cholesterol/HDL & $1.5 \pm 0.2$ & $5.6 \pm 0.1^{*}$ & $1.4 \pm 0.2^{\#}$ \\
LDL/HDL & $0.7 \pm 0.1$ & $2.2 \pm 0.1^{*}$ & $0.8 \pm 0.1^{\#}$ \\
\hline
\end{tabular}

Values depict mean \pm SE for at least $n=6$ animals in each group. ${ }^{*}$ means $p$ $<0.05$ compared to control group and \# means $p<0.05$ compared to STZ diabetic group. 


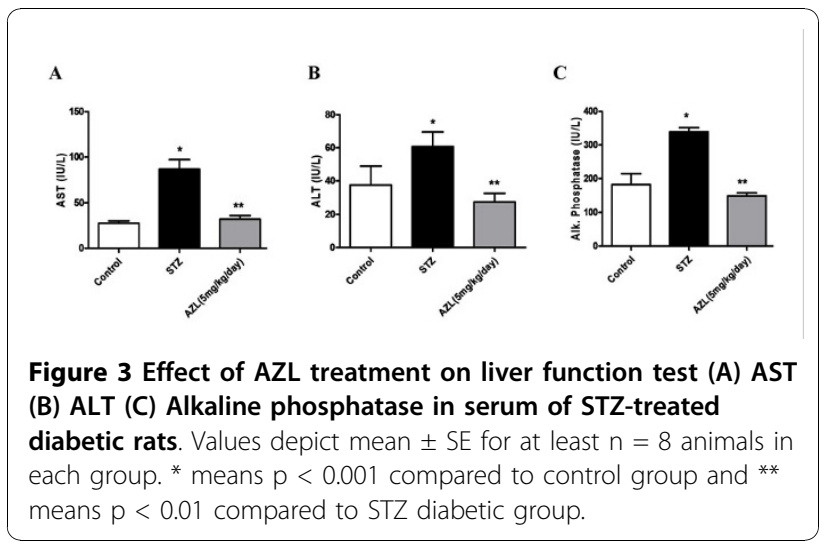

Effect of AZL treatment on antioxidant enzyme levels Levels of SOD (U/mg protein) and GSH (ng/mg protein) were depressed significantly in the diabetic rat (STZ $40 \pm 0.8$ vs. control 13.4 $\pm 2.2, P<0.05$ and GSH $57.9 \pm 32.3$ vs. control $493.5 \pm 46.2, P<0.05$ ), whereas level of catalase ( $\mathrm{mU} / \mathrm{mg}$ protein) increased significantly compared with controls (STZ $3955.6 \pm 457.3$ vs. control
$1102.8 \pm 304.3, P<0.05)$. These different enzyme and non-enzyme antioxidant levels were normalized after AZL treatment (SOD 14.1 $\pm 2.0, P<0.05$; GSH 367.26 $\pm 31.1, P<0.05$ and catalase $996.65 \pm 322.60, P<0.05$ ) (Figure 4D-F).

\section{Discussion}

Diabetes is a metabolic syndrome with a cluster of common clinical disorders that is related with an increased risk for cardiovascular disease [48]. Despite some controversy in the past [49], large patient studies have demonstrated that calcium channel blockers are effective in reducing the mortality and morbidity of cardiovascular disease [50,51]. AZL is one of the cardiobeneficial $\mathrm{CCB}$ that decreases blood pressure without increasing the heart-rate [33,34], prevents cardiac damage [3], reduce glucose intolerance [52] and possesses antioxidant properties [37]. However, there is a significant gap in our knowledge about the cardioprotective action and efficacy of AZL as the effect of AZL on proinflammatory cytokines and altered lipid profile in either diabetic patients or in experimental models of diabetes has not
A

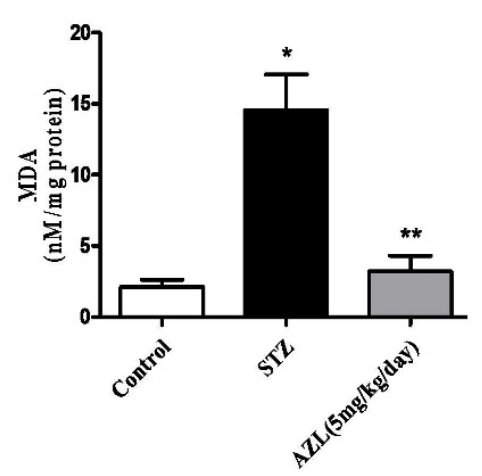

D

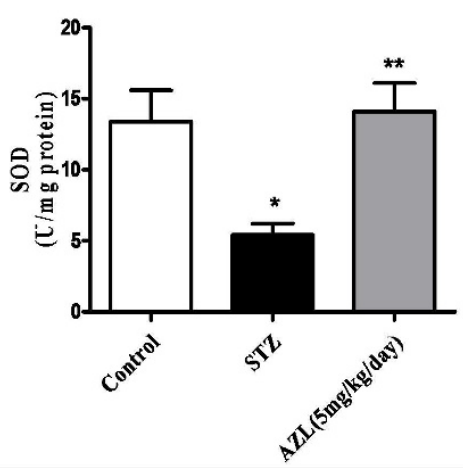

B

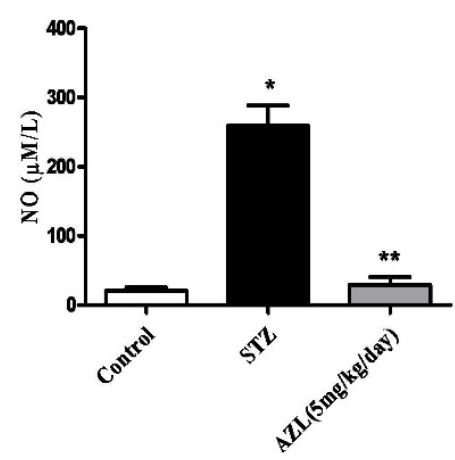

$\mathbf{E}$

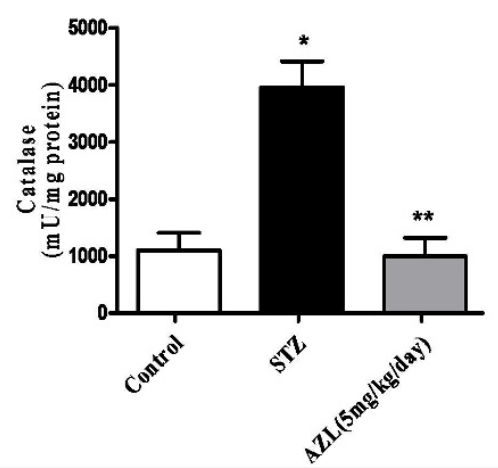

C

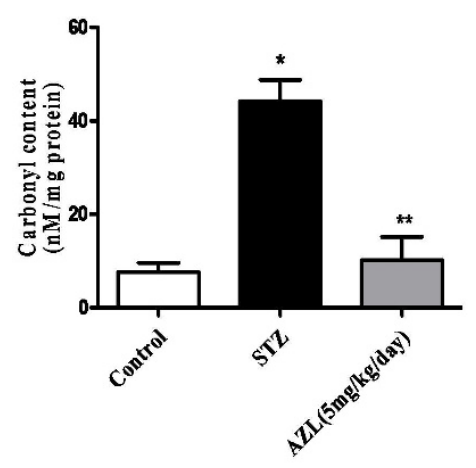

F

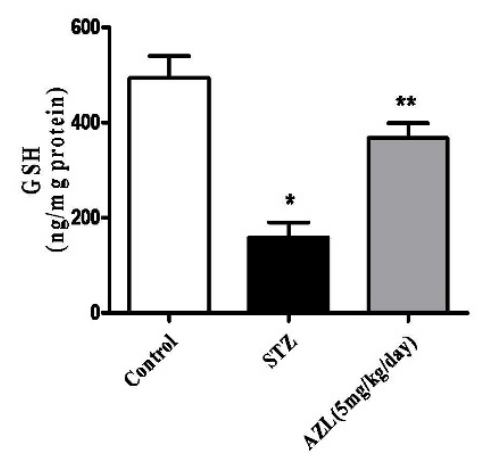

Figure 4 Effect of AZL treatment on levels of oxidative stress markers and antioxidants. (A) Lipid peroxidation (B) Nitric oxide (C) Carbonyl content (D) Superoxide dismutase (E) reduced glutathione (F) Catalase. Values are means \pm SE of 6 rats. * means $p<0.001$ compared to control group, ${ }^{* *}$ means $p<0.01$ compared to STZ diabetic group. 
been studied so far. In the present study, we extensively evaluated the effect of AZL on circulating markers of cardiac damage secondary to diabetes.

Diabetic cardiomyopathy characterized by diastolic dysfunction and left ventricular hypertrophy is usually the terminal condition of heart in diabetes [53]. Our results indicate that 12-week treatment of AZL in diabetic rats proved to be beneficial as it restrained the progression of the metabolic disorders of diabetes. The STZ diabetic rats showed elevated blood glucose levels with reduced levels of serum insulin. Also, there was a notable increase in the $\mathrm{LVW} / \mathrm{BW}$ ratio which signifies cardiac hypertrophy. AZL did not affect the serum insulin levels indicating that it does not affect the function of $\beta$-cells in the pancreas although there was a remarkable improvement in the blood glucose levels. AZL has been shown to improve glucose intolerance in the diabetic mice mainly through inhibition of oxidative stress [52]. This improvement in the blood glucose levels could be attributed to its ancillary properties partially because of its lipid lowering capability and partially because of its antioxidant nature. AZL treatment showed a distinct positive effect on LVW/BW ratio indicating that AZL was able to prevent cardiac hypertrophy which usually sets in as a result of diastolic dysfunction secondary to diabetes.

Elevated hcy level is also an independent risk factor for the development of atherosclerosis as well as a prognostic marker in ischemic heart disease [47,54]. Protein homocysteinylation is a novel example of protein damage that can be attributed to hyperhomocysteinemia [55]. Homocysteinylated proteins were prone to multimerization and underwent gross structural changes that led to their denaturation. Homocysteine thiolactone may also inactivate enzymes responsible for posttranslational modification of connective tissue matrices leading to fibrosis and scarring [56]. Hcy also promotes atherogenesis through oxidative damage that is mediated by cytotoxic free radicals or by the induction of proinflammatory factors [57]. Moreover, under the diabetic condition, endogenously upregulated homocysteine levels induce endothelial-myocyte uncoupling which further aggravate the deteriorating condition of the myocardium [58]. In our study, AZL treatment significantly lowered the elevated Hcy levels indicating that AZL can prevent accumulation of free radicals, atherogenic plaque formation and reducing protein homocysteinylation.

Diabetes is associated with an increase in the oxidative stress that results from exhaustion of cellular antioxidants and depletion of antioxidant enzymes [59]. The results from our study showed that STZ induced diabetic condition resulted in an increase in the lipid peroxidation and protein carbonylation which are direct indicators systemic oxidative stress. This was in conjunction with depletion of superoxide scavenger SOD and reduced glutathione along with an increase in the levels of antioxidant enzyme catalase. AZL treatment in the STZ-diabetic rats reduced the formation of lipid peroxides, nitric oxides and carbonyl content and also restored the levels of SOD and GSH. AZL also reduced the levels of catalase indicating a reduction in the accumulation of reactive oxygen species. This positive beneficial effect of AZL could be directly attributable to its antioxidative nature which is agreement with previous findings $[52,58]$.

It is widely accepted that high levels of circulating cardiac damage markers like troponin I, CK-MB, CK-NAC, $\mathrm{LDH}$ and uric acid represent a powerful and sensitive predictor of increased cardiac complications [60]. In this study, AZL-treated diabetic rats showed a significant improvement in levels of these circulating cardiac damage markers. This indicates that AZL prevents cardiac damage and has beneficial properties far beyond its antihypertensive actions. One of the possible mechanisms of prevention may partially be related to suppression of severe increase in the levels of pro-inflammatory cytokines which was observed in STZ diabetic rats. Our results were in agreement with previous reports where AZL treatment prevented cardiac dysfunction in patients with essential hypertension [34]. This decrease in the cardiac damage markers in the diabetic rats upon AZL treatment supported the hypothesis that AZL reduce the risk of metabolic disorders associated with diabetic. Furthermore, there was no change in serum markers of liver function in AZL treated group compared with untreated diabetic rats, which suggests that AZL treatment did not cause any xenobiotic side effects during the study.

Apart from the altered metabolic condition, diabetes is also an inflammation-prone condition. Hyperglycemiainduced ROS stimulates signal transduction to instigate inflammatory cytokines, e.g. TNF- $\alpha$, IFN- $\gamma$ and TGF- $\beta$ [61]. This leads to systemic inflammation, cardiac dysfunction and exacerbates the severity of diabetes [62]. In the present study, AZL-treated diabetic rats showed effective suppression of these pro-inflammatory cytokines. These results strongly indicate that AZL is a potential agent against diabetes-associated systemic inflammation. We also noticed that AZL increased the levels of the anti-inflammatory and immunosuppressive cytokine IL-4 but did not affect the levels of IL-10. Thus, the resulting reduction in the inflammation in the AZL treated group was due to the stimulation of IL-4 but probably not due the production of anti-inflammatory cytokine IL-10. Inhibition of circulating levels of TNF- $\alpha$, IFN- $\gamma$ and TGF- $\beta$ and an increase in the levels of IL-4 can explain the lowering of serum triglyceride and total cholesterol levels, potentially mediated, at least 
in part, by the increased glucose sensitivity and glucose metabolism in AZL-treated diabetic rats.

In our study, the altered lipid profile observed in the diabetic condition was also abrogated by AZL treatment. AZL improved the serum cholesterol, triglycerides, LDL and VLDL. It also improved the markers of atherogenic risk, (total cholesterol/HDL and LDL/HDL ratio). These findings suggest that AZL possesses lipid lowering activities due to its unique anti-atherogenic properties which also contribute additionally to its cardiovascular protective actions. This is the first report which evaluated the positive effect of AZL on lipid profile in STZ-diabetic rats Diabetes Care27Full Text.

\section{Conclusion}

In conclusion, we showed that AZL treatment abrogated the metabolic disorders in STZ-diabetic rats at least partly through its antioxidant and antiatherogenic properties. These results indicate that the protective effect of AZL might be, at least in part, due to its inhibitory ability on free radical formation, or due to its free radical scavenging ability. These data also indicate that AZL exerts cardioprotection due to its unique modulatory and antioxidative property and thus may be a promising 'cardioprotective DHP' that can even target the secondary cardiac complication of diabetes. This property of AZL could be further extended to clinics and can be used as adjuvant therapy in cardiac complications especially in diabetes.

\section{Acknowledgements}

We thank Dr. G.C. Mishra, Director, National Centre for Cell Science (Pune India) for encouragement and support. We also acknowledge the help from the staff of the experimental animal facility at National Centre for Cell Science. We thank Dr. Prashant Patil for help with the rat serum biochemistry profiling.

\section{Author details}

${ }^{1}$ National Centre for Cell Science, NCCS Complex, Pune University Campus, Ganeshkhind Road, Pune-411007, Maharashtra, India. ${ }^{2}$ Interdisciplinary School of Health Sciences, University of Pune, Ganeshkhind, Pune-411007,

Maharashtra, India.

\section{Authors' contributions}

VK and SK contributed equally to the experimental designing and bench work. ASP performed the Hcy estimation and SLS conceived and designed the study. All authors have read and approved the final manuscript.

\section{Competing interests}

The authors declare that they have no competing interests.

Received: 16 August 2010 Accepted: 1 December 2010 Published: 1 December 2010

\section{References}

1. Thom T, Haase N, Rosamond W, Howard VJ, Rumsfeld J, Manolio T, Zheng ZJ, Flegal K, O'Donnell C, Kittner S, et al: Heart disease and stroke statistics-2006 update: a report from the American Heart Association Statistics Committee and Stroke Statistics Subcommittee. Circulation 2006, 113(6):e85-151.

2. Reasner CA: Reducing cardiovascular complications of type 2 diabetes by targeting multiple risk factors. J Cardiovasc Pharmacol 2008, 52(2):136-144.
3. Nishiya D, Enomoto S, Omura T, Matsumoto R, Kusuyama T, Izumi $Y$ Iwao H, Takeuchi K, Yoshiyama M: The long-acting Ca2+-channel blocker azelnidipine prevents left ventricular remodeling after myocardial infarction. J Pharmacol Sci 2007, 103(4):391-397.

4. Hussain MJ, Peakman M, Gallati H, Lo SS, Hawa M, Viberti GC, Watkins PJ, Leslie RD, Vergani D: Elevated serum levels of macrophage-derived cytokines precede and accompany the onset of IDDM. Diabetologia 1996, 39(1):60-69.

5. Kini AS, Kim MC, Moreno PR, Krishnan P, Ivan OC, Sharma SK: Comparison of coronary flow reserve and fractional flow reserve in patients with versus without diabetes mellitus and having elective percutaneous coronary intervention and abciximab therapy (from the PREDICT Trial). Am J Cardiol 2008, 101(6):796-800.

6. Geddes J, Deans KA, Cormack A, Motherwell D, Paterson K, O'Reilly DS, Fisher BM: Cardiac troponin I concentrations in people presenting with diabetic ketoacidosis. Ann Clin Biochem 2007, 44(Pt 4):391-393.

7. Mandosi E, Fallarino M, Gatti A, Carnovale A, Rossetti M, Lococo E, Buchetti B, Filetti S, Lenti L, Morano S: Atorvastatin downregulates monocyte CD36 expression, nuclear NFkappaB and TNFalpha levels in type 2 diabetes. J Atheroscler Thromb 2010, 17(6):539-545.

8. Motomura T, Okamoto M, Kitamura T, Yamamoto H, Otsuki M, Asanuma N Takagi M, Kurebayashi S, Hashimoto K, Sumitani S, et al: Effects of pitavastatin on serum lipids and high sensitivity C-reactive protein in type 2 diabetic patients. J Atheroscler Thromb 2009, 16(5):546-552.

9. Guha A, Harmancey R, Taegtmeyer H: Nonischemic heart failure in diabetes mellitus. Current Opinion in Cardiology 2008, 23(3):241-248, 210.1097/HCO.1090b1013e3282fcc1092fa.

10. Oliveira PJ, Seica R, Coxito PM, Rolo AP, Palmeira CM, Santos MS, Moreno AJ: Enhanced permeability transition explains the reduced calcium uptake in cardiac mitochondria from streptozotocin-induced diabetic rats. FEBS Lett 2003, 554(3):511-514.

11. Ye G, Metreveli NS, Donthi RV, Xia S, Xu M, Carlson EC, Epstein PN: Catalase protects cardiomyocyte function in models of type 1 and type 2 diabetes. Diabetes 2004, 53(5):1336-1343.

12. Zhou G, Li X, Hein DW, Xiang X, Marshall JP, Prabhu SD, Cai L: Metallothionein suppresses angiotensin II-induced nicotinamide adenine dinucleotide phosphate oxidase activation, nitrosative stress, apoptosis, and pathological remodeling in the diabetic heart. J Am Coll Cardiol 2008, 52(8):655-666

13. Nian M, Lee $P$, Khaper N, Liu P: Inflammatory cytokines and postmyocardial infarction remodeling. Circ Res 2004, 94(12):1543-1553.

14. Goldhaber J: Free radicals enhance $\mathrm{Na}+/ \mathrm{Ca} 2+$ exchange in ventricular myocytes. Am J Physiol 1996, 271(3 Pt 2):H823-833.

15. Zella D, Barabitskaja O, Burns JM, Romerio F, Dunn DE, Revello MG, Gerna G, Reitz MS Jr, Gallo RC, Weichold FF: Interferon-gamma increases expression of chemokine receptors CCR1, CCR3, and CCR5, but not CXCR4 in monocytoid U937 cells. Blood 1998, 91(12):4444-4450.

16. Ina $Y$, Koide $Y$, Nezu N, Yoshida TO: Regulation of HLA class II antigen expression: intracellular signaling molecules responsible for the regulation by IFN-gamma and cross-linking of Fc receptors in HL-60 cells. J Immunol 1987, 139(5):1711-1717.

17. Rotnes JS, Aas V, Iversen JG: Interferon-gamma modulates cytosolic free calcium in human neutrophilic granulocytes. Eur J Haematol 1994, 53(2):65-73.

18. Singh K, Balligand JL, Fischer TA, Smith TW, Kelly RA: Regulation of cytokine-inducible nitric oxide synthase in cardiac myocytes and microvascular endothelial cells. Role of extracellular signal-regulated kinases 1 and 2 (ERK1/ERK2) and STAT1 alpha. J Biol Chem 1996, 271(2):1111-1117.

19. Avila G, Medina IM, Jimenez E, Elizondo G, Aguilar Cl: Transforming growth factor-beta1 decreases cardiac muscle L-type Ca2+ current and charge movement by acting on the Cav1.2 mRNA. Am J Physiol Heart Circ Physiol 2007, 292(1):H622-631.

20. Mavroidis M, Capetanaki Y: Extensive induction of important mediators of fibrosis and dystrophic calcification in desmin-deficient cardiomyopathy. Am J Pathol 2002, 160(3):943-952.

21. Wang $Y$, Feng W, Xue W, Tan Y, Hein DW, Li XK, Cai L: Inactivation of GSK3beta by metallothionein prevents diabetes-related changes in cardiac energy metabolism, inflammation, nitrosative damage, and remodeling Diabetes 2009, 58(6):1391-1402. 
22. Finck BN, Lehman JJ, Leone TC, Welch MJ, Bennett MJ, Kovacs A, Han X, Gross RW, Kozak R, Lopaschuk GD, et al: The cardiac phenotype induced by PPARalpha overexpression mimics that caused by diabetes mellitus. $J$ Clin Invest 2002, 109(1):121-130.

23. Poornima IG, Parikh P, Shannon RP: Diabetic cardiomyopathy: the search for a unifying hypothesis. Circ Res 2006, 98(5):596-605.

24. Cai L, Wang J, Li Y, Sun X, Wang L, Zhou Z, Kang YJ: Inhibition of superoxide generation and associated nitrosative damage is involved in metallothionein prevention of diabetic cardiomyopathy. Diabetes 2005, 54(6):1829-1837.

25. Cai $L$ : Suppression of nitrative damage by metallothionein in diabetic heart contributes to the prevention of cardiomyopathy. Free Radic Biol Med 2006, 41(6):851-861.

26. Kumar S, Kain V, Sitasawad SL: Cardiotoxicity of calmidazolium chloride is attributed to calcium aggravation, oxidative and nitrosative stress, and apoptosis. Free Radic Biol Med 2009, 47(6):699-709.

27. Davidson SM, Duchen MR: Calcium microdomains and oxidative stress. Cell Calcium 2006, 40(5-6):561-574.

28. Luo J, Xuan YT, Gu Y, Prabhu SD: Prolonged oxidative stress inverts the cardiac force-frequency relation: role of altered calcium handling and myofilament calcium responsiveness. J Mol Cell Cardiol 2006, 40(1):64-75.

29. Persoon-Rothert M, Egas-Kenniphaas JM, van der Valk-Kokshoorn EJ, Buys JP, van der Laarse A: Oxidative stress-induced perturbations of calcium homeostasis and cell death in cultured myocytes: role of extracellular calcium. Mol Cell Biochem 1994, 136(1):1-9.

30. Grossman E, Messerli FH: Calcium antagonists. Prog Cardiovasc Dis 2004 47(1):34-57.

31. Takahashi T, Momiyama A: Different types of calcium channels mediate central synaptic transmission. Nature 1993, 366(6451):156-158.

32. Nathan S, Pepine CJ, Bakris GL: Calcium Antagonists: Effects on CardioRenal Risk in Hypertensive Patients. Hypertension 2005, 46(4):637-642.

33. Yoshinaga $\mathrm{K}$, limura $\mathrm{O}$, Abe $\mathrm{K}$, Saruta $\mathrm{T}$, Kurokawa K, Ishii M: A multicenter double-blind comparison study of CS-905 (azelnidipine) with nitrendipine in patients with essential hypertension. Journal of Clinical Therapeutic Medicine 2000, 16:671-739.

34. Kobayashi K, Kamimura S, Okada Y, Manako K, Ikeda T, Kondo A: Long-term effects of CS-905 (azelnidipine) on diurnal blood pressure variation and hemodynamics in patients with essential hypertension. Journal of Clinical Therapeutic Medicine 2000, 16:269-281.

35. Nakano K, Egashira K, Ohtani K, Gang Z, Iwata E, Miyagawa M, Sunagawa K: Azelnidipine has anti-atherosclerotic effects independent of its blood pressure-lowering actions in monkeys and mice. Atherosclerosis 2008, 196(1):172-179.

36. Matsui T, Yamagishi S, Nakamura K, Kikuchi S, Inoue H: Azelnidipine, a dihydropyridine-based calcium antagonist, inhibits angiotensin IIinduced oxidative stress generation and downregulation of pigment epithelium-derived factor mRNA levels in microvascular endothelial cells. Drugs Exp Clin Res 2005, 31(5-6):215-219.

37. Koyama Y, Takeishi Y, Takahashi H, Shishido T, Arimoto T, Niizeki T, Harada M, Suzuki S, Kitahara T, Sasaki T, et al: Azelnidipine inhibits H2O2induced cell death in neonatal rat cardiomyocytes. Cardiovasc Drugs Ther 2007, 21(1):69-72.

38. Maggi CA, Meli A: Suitability of urethane anesthesia for physiopharmacological investigations in various systems. Part 2: Cardiovascular system. Cellular and Molecular Life Sciences 1986, 42(3):292-297.

39. Fernandez-Twinn DS, Wayman A, Ekizoglou S, Martin MS, Hales CN, Ozanne SE: Maternal protein restriction leads to hyperinsulinemia and reduced insulin-signaling protein expression in 21-mo-old female rat offspring. Am J Physiol Regul Integr Comp Physiol 2005, 288(2):R368-373.

40. Lowenthal EA, Mayo MS, Cornwell PE, Thornley-Brown D: Homocysteine Elevation in Sickle Cell Disease. J Am Coll Nutr 2000, 19(5):608-612.

41. Gupta YK, Sharma M, Chaudhary G: Pyrogallol-induced hepatotoxicity in rats: a model to evaluate antioxidant hepatoprotective agents. Methods Find Exp Clin Pharmacol 2002, 24(8):497-500.

42. Mihara M, Uchiyama M: Determination of malonaldehyde precursor in tissues by thiobarbituric acid test. Anal Biochem 1978, 86(1):271-278.

43. Ellman GL: Tissue sulfhydryl groups. Arch Biochem Biophys 1959, 82(1):70-77.
44. Bradford MM: A rapid and sensitive method for the quantitation of microgram quantities of protein utilizing the principle of protein-dye binding. Anal Biochem 1976, 72:248-254.

45. Levine RL, Garland D, Oliver CN, Amici A, Climent I, Lenz AG, Ahn BW, Shaltiel S, Stadtman ER: Determination of carbonyl content in oxidatively modified proteins. Methods Enzymol 1990, 186:464-478.

46. Lowry $\mathrm{OH}$, Rosebrough NJ, Farr $\mathrm{AL}$, Randall RJ: Protein measurement with the Folin phenol reagent. J Biol Chem 1951, 193(1):265-275.

47. Wald DS, Law M, Morris JK: Homocysteine and cardiovascular disease: evidence on causality from a meta-analysis. BMJ 2002, 325(7374):1202

48. Grundy SM, Benjamin IJ, Burke GL, Chait A, Eckel RH, Howard BV, Mitch W, Smith SC Jr, Sowers JR: Diabetes and cardiovascular disease: a statement for healthcare professionals from the American Heart Association. Circulation 1999, 100(10):1134-1146.

49. Messerli $\mathrm{FH}$ : What, if anything, is controversial about calcium antagonists? Am J Hypertens 1996, 9(12 Pt 2):177S-181S.

50. O'Connor CM, Carson PE, Miller AB, Pressler ML, Belkin RN, Neuberg GW, Frid DJ, Cropp AB, Anderson S, Wertheimer JH, et al: Effect of amlodipine on mode of death among patients with advanced heart failure in the PRAISE trial. Prospective Randomized Amlodipine Survival Evaluation. Am J Cardiol 1998, 82(7):881-887.

51. Chen J, Cha-Molstad H, Szabo A, Shalev A: Diabetes induces and calcium channel blockers prevent cardiac expression of proapoptotic thioredoxin-interacting protein. Am J Physiol Endocrinol Metab 2009, 296(5):E1133-1139.

52. Iwai M, Li HS, Chen R, Shiuchi T, Wu L, Min LJ, Li JM, Tsuda M, Suzuki J, Tomono $Y$, et al: Calcium channel blocker azelnidipine reduces glucose intolerance in diabetic mice via different mechanism than angiotensin receptor blocker olmesartan. J Pharmacol Exp Ther 2006, 319(3):1081-1087.

53. Raev DC: Which left ventricular function is impaired earlier in the evolution of diabetic cardiomyopathy? An echocardiographic study of young type I diabetic patients. Diabetes Care 1994, 17(7):633-639.

54. Kerkeni M, Addad F, Chauffert M, Chuniaud L, Miled A, Trivin F, Maaroufi K: Hyperhomocysteinemia, paraoxonase activity and risk of coronary artery disease. Clin Biochem 2006, 39(8):821-825.

55. Jakubowski H: Protein homocysteinylation: possible mechanism underlying pathological consequences of elevated homocysteine levels. FASEB J 1999, 13(15):2277-2283.

56. Liu G, Nellaiappan K, Kagan HM: Irreversible inhibition of lysyl oxidase by homocysteine thiolactone and its selenium and oxygen analogues. Implications for homocystinuria. J Biol Chem 1997, 272(51):32370-32377.

57. Austin RC, Lentz SR, Werstuck GH: Role of hyperhomocysteinemia in endothelial dysfunction and atherothrombotic disease. Cell Death Differ 2004, 11(Suppl 1):S56-64.

58. Mishra PK, Tyagi N, Sen U, Joshua IG, Tyagi SC: Synergism in hyperhomocysteinemia and diabetes: role of PPAR gamma and tempol. Cardiovasc Diabetol 2010, 9:49.

59. Robertson RP, Harmon J, Tran PO, Tanaka Y, Takahashi H: Glucose toxicity in beta-cells: type 2 diabetes, good radicals gone bad, and the glutathione connection. Diabetes 2003, 52(3):581-587.

60. Howard-Alpe GM, Sear JW, Foex P: Methods of detecting atherosclerosis in non-cardiac surgical patients; the role of biochemical markers. $\mathrm{Br} \mathrm{J}$ Anaesth 2006, 97(6):758-769.

61. Hori $M$, Nishida $K$ : Oxidative stress and left ventricular remodelling after myocardial infarction. Cardiovasc Res 2009, 81(3):457-464.

62. Mohamed-Ali V, Armstrong L, Clarke D, Bolton CH, Pinkney JH: Evidence for the regulation of levels of plasma adhesion molecules by proinflammatory cytokines and their soluble receptors in type 1 diabetes. J Intern Med 2001, 250(5):415-421.

doi:10.1186/1475-2840-9-82

Cite this article as: Kain et al:: Azelnidipine protects myocardium in hyperglycemia-induced cardiac damage. Cardiovascular Diabetology 2010 9:82. 